\title{
Artificial lighting in the future cities: creation of architecture by the physics of light
}

\begin{abstract}
The lighting is considered one of the most important factors in urban design and due to its important role in human life; this factor should be further recognized. Artificial lighting should be as profitable as natural lighting and result in material and spiritual growth of cities and humans. Unfortunately, there is not an integrated lighting, appropriate to specific goals for a wide area such as a city: a lighting that helps functional and social factors direct and transfer the population into different segregated areas of the city, in addition to achievements including beauty, variation and Memorability, economy and tourism, population growth, locating and better enjoying of the roads. For this purpose, a plan was provided in which linear lighting with different colors is used in every segregated area of the city that is the main factor for directing the population to each area and eliminates innercity problems, such as waste of time and violence. Thus, in this study, descriptive analytical (qualitative and quantitative) research was used as survey and library method and assumed that the study objectives are achieved after completing the project and the obtained results proved the hypothesis. Also, since the project is profitable and it also helps heighten the material and spiritual quality of humans, any person with common sense would run it.
\end{abstract}

Keywords: memorability, lighting, cities, economic
Volume 3 Issue I - 2017

Amir Reza Goudarzi

Department of Architecture, Islamic Azad University, Iran

Correspondence: Amir Reza Goudarzi, Department of Architecture, Islamic Azad University, Iran

Tel+9893927I 2503, Email amirrezagoudarzi93@gmail.com

Received: March 24, 2017| Published: June 30, 2017

\section{Introduction}

Light and darkness have always been symbols of contradiction, knowledge and ignorance in human history. Consequently, the distribution and qualification of natural light have been important not only for responding to human life requirements but also as tools for understanding the universe. The importance of natural light and its function as an efficient source of brightness during the day remain important in the area of architecture and urban development. However, attempts at "artificial lighting" by lighting technology researchers over the past 50 years have contributed to the improvement of night spaces, particularly, public spaces, and they cannot be ignored. ${ }^{1}$

Light, as the most important element of the universe, plays a significant role in the quality of human life. Combination of art with light and shadow, and the use of light in industry, medicine, and astronomy are all possible. Humans deal with light frequently, but they do not react in the same manner to all light. Moreover, humans' feelings alone define their reaction to light. Since Through centuries, mystics have composed poems in praising light as a spiritual essence. The desire to face light when worshipping god in Zoroastrianism is clear in the following quote by Zoroaster: "since god or the universal light cannot be seen by our material eyes, then one should look at and face visible light with his material eyes and by doing so he should guide his spiritual viewing conscience towards the spiritual light that is Ahuramazda". ${ }^{2}$ In the Koran, light has a special position: "god is the light of the skies and the earth" (Surah Noor, verse 25), and there is a quote from the prophet that adds a cosmologic aspect to this verse: "The first thing that god created was light". ${ }^{3}$

Unfortunately, there are very little or no resources for the context of this study, as well as targeted urban lighting. One of the translated resources in this regard, is the translated book of Gardner and Raphael (2007) entitled "The change in the use of lighting (recounting architecture)" in which the most advanced and the latest lighting technologies have been described in six parts. One of these parts is about historic buildings and cultural heritage in which, lighting of monuments like the Eiffel tower, a monument to Prince Albert and the Temple of Luxor, Egypt, have been presented aiming at minimum destruction on irrecoverable tissue of the building. Nonetheless, in all the cases the idea of the lighting designer is referred to and the lighting method is not mentioned. Another Persian literature in this area was written by Ahmadian ${ }^{4}$ entitled "Introduction to the Principles of Lighting Design". Contents of the book include introduction to the basics of lighting, lighting equipments and lighting calculations that have been proposed for all urban spaces and buildings.

In the journal "Danesh Nama" some articles have been published about the lighting of some historic buildings such as, Chaharbagh School, Siose Bridge and Vank Cathedral. In non-Persian resources also, there has been a brief description of urban spaces and historic buildings lighting in some cases, however, unfortunately, no research has been done on lighting of urban spaces as city zoning. In the book, written by Phillips ${ }^{6}$ entitled "the surrounding light" topics such as: lighting of buildings and the impact of various factors such as the reason for lighting of the building at night, the relationship between daily and nightly appearance of the building and the emphasis on the unity of architecture, daily appearance of lighting equipment, color and position of the building in the urban context have been described. Santan ${ }^{7}$ in his work entitled "light of the urban space" has put together pictures of daily or nightly look of buildings and urban spaces (modern and historical), that in addition to the daily and nightly look of the building, illuminated elements, components and parts have also been noted. ${ }^{8}$ Throughout history, architects have considered the use of daylight when designing structures. However, after the discovery of electricity and invention of the electric lamp, which provided the possibility to artificially illuminate interior spaces, the use of natural daylight diminished. The experience of the past 
hundred years showed that the humans' material and mental need for daylight is very profound and more fundamental than that for artificial illumination. Therefore, researchers in developed countries have been studying daylight and its exploitation since many years. In this regard, international communities such as European Commission on Illumination (CIE), Illuminating Engineering Society of North America (IESNA), China Illuminating Engineering Society (CIES), India Illuminating Engineering Society (ILSE), and other scientific and research communities in Australia and Canada have been researching and producing lighting standards for natural and artificial light. Over the past few years, owing to the development of knowledge in the country and the interest of a few university students in researching the use of natural lighting in architecture, some theoretical studies have been conducted in the field of daylight calculation in addition to a few studies based on field surveys on natural lighting conditions in academic or office spaces. A few of these studies are Tahbaz, ${ }^{9}$ Sanati, ${ }^{10}$ Feizmandm, ${ }^{11}$ \& Kazemzadeh. ${ }^{12}$ Establishment of the Illuminating and Lighting Engineering Society of Iran is another positive step in this regard. Moreover, software developers have created tools for the determining the reasons for success or failure of lighting in different spaces. With the arrival of this knowledge to Iran, a new path has been created for studying daylight in historical spaces. ${ }^{13}$

Goals that we're seeking for at this paper are achieved by targeted, conscious and planned lighting of the city. Accordingly, each functional area of the city has a way to access that instead of enjoying large boards limiting visibility, the line of the illuminated path given the color specified for each area is used and the illuminated paths finally reaches its functional areas of which the lighting design is determined by the given color. This in addition to beautification and variation of urban environment minimizes or prevents fear, stress and anxiety in the city especially for guests of the city. Also, due to the separation of urban spaces by using the method, confusion and waste of time of people are prevented and the transportation is accelerated. Our objectives also include urban discipline that we reached the purpose somewhat by this method and thereby it results in the control of the city and creates better security for citizens. However, our hypothesis is on the basis that imposing such a way as colored light bands in the hospital that guide clients to the relevant area, causes to establish the mentioned goals in the city and successes achieved. All questions that are raised now are on the basis whether the implementation of such a plan has economic, social and cultural efficiency? Is the implementation of such a plan feasible in today's cities without any spatial separation?

\section{Research methodology}

In this study, descriptive-analytical (quantitative and qualitative) research method was used as survey and library method. Using a questionnaire, we questioned some individuals randomly that according to the objective of this article, questions were raised on psychology and their thoughts and feelings in dealing with the environment and the emotions, fear, comfort, safety, and their understanding of the environmental were examined an $22 \mathrm{~d}$ we all were seeking to consider all aspects of the research to obtain the best results. We tried our best to cover all research aspects so that the best results could be obtained. In addition, we studied a few books on subjects in relevant fields to be able to interpret the results accurately.

\section{Findings}

In this research, 20 ( 8 male and 12 female) individuals were asked to answer a questionnaire.

\section{Descriptive statistics}

\section{Frequency distribution of age}

Based on Table $1 \&$ Figure 1, 16 of the respondents are 25-30 years old, and this age group has the highest frequency

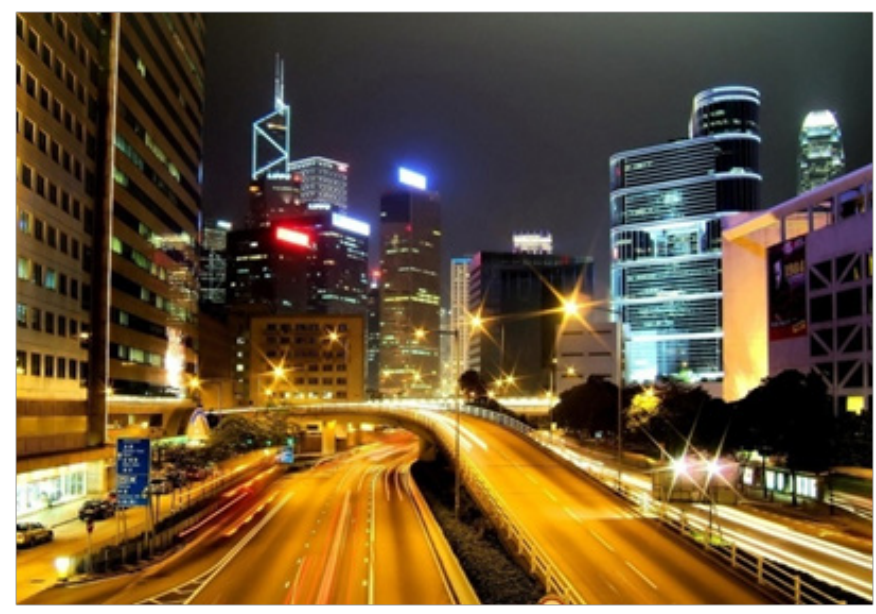

Figure I Beauty, harmony, proportion, composition, smoothness and density of lighting can be seen

Table I Age distribution

\begin{tabular}{llllll}
\hline & & Frequency & Percent & $\begin{array}{l}\text { Valid } \\
\text { percent }\end{array}$ & $\begin{array}{l}\text { Cumulative } \\
\text { percent }\end{array}$ \\
\hline \multirow{3}{*}{ Valid } & $25-30$ & 16 & 10.6 & 84.6 & 84.6 \\
& $30-35$ & 2 & 1 & 7.7 & 92.3 \\
& $35-40$ & 2 & 1 & 7.7 & 100 \\
\multirow{2}{*}{ Missing } & System & 182 & 12.5 & 100 & \\
Total & & 208 & 87.5 & & \\
\hline
\end{tabular}

\section{Correlation}

To determine the existence of a relationship between the two variables, we investigated the correlation between them. Accordingly, since this outcome has a lower than 0.05 significant (i.e. 0.007), it cannot be zero and the correlation between these two variables (The project with Goals of research). The corresponding correlation coefficient is 0.186 for a dataset comprising 208 entries.

\section{Simple linear regression}

In regression, we estimate a mathematical equation and analyze it such that the quantity of an unknown variable can be determined using said equation and known variable(s). The result includes 4 outcomes. The first outcome shows the entered independent variables, removed variables, and the method used for determining regression. The second outcome lists the multiple correlation coefficient, coefficient of determination, adjusted coefficients, and standard error of the estimates, respectively.

The third outcome is from a regression analysis for evaluating the certainty of the existence of a linear relationship between the two variables. According to the table below, the significance level is less than $5 \%$, thus confirming the linearity of the relationship between the two variables. 
For testing, each of the coefficients in column B is assumed to be zero. If $\alpha$ and $\beta$ are the constant value and the slope of the population regression line, respectively, the hypothesis testing for these two quantities can be written as follows:

$$
\begin{aligned}
& H 0: \alpha=0 \text { HO: } \beta=0 \\
& H 1: \alpha \neq 0 \text { H1: } \beta \neq 0
\end{aligned}
$$

Because the significance of the regression coefficient equality test is less than $5 \%$ and the constant value is zero, the hypothesis that these two coefficients are equal to zero is rejected, and they are not removed from the regression equation.

\section{Explanations}

\section{Beauty}

The use of artificial lighting in addition to illuminating, also offers other functions. Landscaping, spiritual knowledge and understanding of the environment, the use of colored lights instead of painting spaces and etc are a small part of its functions. In today's cities, especially cities that are designed to segregate multiple areas there is a need for guiding people to access different areas. Even in cities that were not segregated there is a need for interesting, attractive and modern guide. If we use artificial light with different colors where each color indicates each area of the city, so that the city is covered with signage marked by artificial light with different colors and every light color is the guide of the desired functional area that it finally removes many unknowns and difficulties of the major cities. Also each area according to the color of the light will be illuminated and the light of the entire area has the designated color. In addition to the functional order in the city, landscaping, use of technology, diversity in the city, the plan can lead to mobility and discovery of talents and silent elite in the lighting field.

\section{Economic feasibility of the project}

The economic feasibility of the project will also be very important. For this purpose, by reserving a percentage of annual electricity consumption and dedicating it to this project, low-consumption culture is taught to people and also the low consumption of electricity saved by people will lead to the implementation of the project, and people will enjoy a beautiful city.

The improper choice of color and light material will attract insects which in turn cause serious damage to urban or chemical impacts and irreversible damages to painted surfaces. ${ }^{14}$ As light sources that have higher thermal effects, may be useful against moisture and the plurality of types of algae and microorganisms, they can lead to harmful humidity changing, air flow intensification and excessive growth of some plants (www.aftabir.com). Furthermore, equipments used without planning and by trial and error for the lighting of the monuments; in addition to spending a lot of time and energy, it also creates the possibility of not reaching the desired result and may cause damage to building and space, eye hurt, safety risks and huge fire. ${ }^{14}$ So thinking ahead and choosing the right factors can prevent potential problems and loss of capital.

The tourism industry also plays an important role in economic growth and representing the historical and the cultural background of the countries. The industry matters in the social-economic development of the countries to the extent that economists have called it invisible exports. ${ }^{15,16}$ The study of this issue from the perspective of the economy of tourism is important and creates avariety of attractions from scientific and cultural aspects. ${ }^{14}$ Now, according to this project, which is a new perspective on urban design, we attract tourism and thus investment and money, in practice. Because according to the research questionnaire, people's interest in the project was realized.

\section{Variation and memorability}

The lighting is based on two states, variation in the appearance of the city at night by lighting or the similarity of the appearance of the city to what we see during the day. About the former state, it must be said that even though the designers intends the similarity of spaces and buildings during nights and days, this is not possible. Since electric lamps as light sources of the night are not compatible with the sun and sky of the day in size and power. Thus, it can be rarely seen that the purpose of lighting a building or street at night, is in fact, the imitation of its daily appearance. ${ }^{17}$ In a world that reflects contradictions and differences are parts of the world's nature, why one should establish a plan that evokes similarity. The project must comply with different functions of night and day, meet the needs of the city and the citizens and in both cases nurture a sense of beauty and memorability.

Due to factors such as security, legibility, memorability, vitality, local identity, retaining visual quality of walls, volumes and natural environment at different times of the day and also creating a different a different atmosphere, which is made possible through a variation in lighting, today lighting design has become one of the most important issues in securing, landscaping and artistic projects of cities. ${ }^{18}$ In designing this model of lighting, conditions such as prioritizing and selecting patterns are based on creativity, innovation, state of being poetic and entertaining of the ideas and also considering different positions of free space such as wind, rain and climate change, as well as possible damage and considerations such as minimum energy consumption, no scratches, holes in surfaces and prevention of the movement of the population. ${ }^{19}$

The public space in a city should be visually different, more readable and memorable than other urban spaces while enjoying a specific identity of its own. In fact, a public space to be committed to the memories and yet plays role in the overall identity of the city, should have skillful coherence and consistency with other urban spaces while being different and special. Because today the majority of the citizens "perception of the city and urban space takes place at night, nightlife in the city has become a concern for city managers and planners. In fact, the majority of the identity of the public spaces of the city is dependent on the urban appearance at night. ${ }^{20}$ Accordingly, based on the respondents to the questionnaire it was found that most of them find the beautiful city, memorable and safe at night, provided that it has proper and integrated lighting and there is not a large difference and scattering of light colors within the environment, but every light overlaps its light spectrum in the same environment.

\section{Population growth}

The world we live in is constantly changing. ${ }^{20}$ With the increase in urban population in recent years, cities have faced physical development. ${ }^{21}$ Development and growth of metropolitan cities attract and deform a large part of the finest and the most appropriate lands of the cities including agricultural land and natural resources, this leads to fragmentation of natural ecosystems and negatively affects biodiversity of the region. 22

This issue creating positive and negative factors in different fields must be taken seriously. Large populationis associated with crowding and stress. In this regard, this proposal, in addition to the influencing 
factors of beauty and relaxing, prevents mistakes and sinking of population and gives a new order to the population and reduces the negative effects such as non-cultural approaches and citizens are required to carry out tasks according to their needs. The use of aerial images. Aerial images can help us in proper design, placement and routing of linear lighting to minimize the patterns and the complexity of the project.

One of the most widely used models to decompose mixed pixels in an urban environment is the linear spectral mixing model, which can be divided into two main spectral and spatial separation models. In spectral separation model, using the spectral information of the image content, we can calculate the percentage of each ingredient in mixed pixels. Spectral data are usually obtained from three sources: experimental data, terrain data and super-spectral images. In the second group, spatial separation models, using spatial information of the image content the reflectivity spectrum of any components of the image can be determined in some parts of the electromagnetic spectrum. ${ }^{23}$

\section{The role of vehicles}

Today there is almost no city without cars. It is currently one of the problems of urban planners and environmental researchers and one must think of a solution to make their paths targeted. Taking advantage of this research project, initial steps can be taken to resolve this problem. Modernism and especially the introduction of the theory of "the right city with personal vehicle" reduced the importance of sidewalks ${ }^{24}$ and modern urban life was considered synonymous to the use of vehicles. ${ }^{25}$ And the interaction between transportation and urban development model as well as higher levels of wealth and social welfare, increased dependence on cars and urban growth on one hand, and urbanization growth and centralized urban activities on the other hand unbridled pace of life in urban communities especially in developing countries, all led to increasing motorization of the community. As in many cities, often more than eighty percent of trips are made by cars. ${ }^{26-28}$ In this regard, every year the number of vehicles on the road and especially on the streets of big cities increases and it is expected that this increase will continue and even increase in the future. ${ }^{29}$

\section{Locating}

During the past decades, efforts have been done to create locating models considering more features of the real world. One of the new features developed in new methodologies of operations research is the concept of "balance". Customers of a system expect a fair behavior based on social laws. Therefore, locating decisions of the problem could be the establishment of the centers in places where users are treated in a fair way with regard to certain criteria. A classification of locating targets, divided them into three categories based on physical concepts of tensile forces, pressure forces and balance:

1. The first category includes tensile targets and somehow tends to guarantee the proximity of the facilities and demand spots $\mathrm{s}$, such as minimizing transportation costs or maximizing market share. Most research has been done until the mid1960s, included these targets. These models reused for locating desired facilities or attraction. Among thousands of models that have been studied, four locating models including p-middle, p-center, locating with unlimited capacity and allocation can be noted and they were known as the problems of template locating and continue to play a prominent role in this area.

2. Since the 1970 s, researchers began to study models in which customers want to keep their facilities and their settlement in the farthest point. These objectives are named as pressure objectives, including location of undesirable or harmful facilities and dispersion models.

3. The third set of goals is the achievement of balance. These models attempt to locate the facilities so that, for example, points are located in a "similar" distance from each other as possible. Another feature considered in this locating model is how to select the service provider. In this case, it is often assumed that customers choose the closest facility. ${ }^{30}$

Today, violence and fear of violence have been raised as a pervasive concern in all societies. The influence of violence on everyday life becomes a reality in many countries and cities; as described with titles such as domestic, common and even abandoned violence. In such circumstances, the policies of organizations combating violence which often focus directly on the offender have not been very successful and this has led to the consideration of factors influencing the occurrence of violence and the underlying factors. One of the factors considered by urban planners, sociologists and environment psychologists in recent decades have been urban spaces and consequently defenseless urban spaces. One might say that in any given urban space, there is a certain amount of violence, however the violence is not randomly distributed in the city; Because infected or defenseless areas are the places where all kinds of violence are occurring, while violence does not occur in any other place. ${ }^{29,30}$ Separation of urban areas can be a key factor in reducing violence, however, guiding and unavailability of any area or confusion in finding any area can also be a cause of violence, but by utilizing a guiding linear lighting design, confusion, stress and waste of time and the relevant violence and anger will be eliminated Tables 1-4.

Table 2 Statistics (Indicators describing data)

\begin{tabular}{lllll}
\hline & & The project & Goals of research \\
\hline & \multirow{3}{*}{ The project } & Correlation Coefficient & I & $.186^{* * *}$ \\
& & Sig. (2-tailed) &. & 0.007 \\
Spearman's rho & $\mathrm{N}$ & 208 & 208 \\
& & Correlation Coefficient & $.186 * *$ & 1 \\
& Goals of research & Sig. (2-tailed) & 0.007 &. \\
& $\mathrm{~N}$ & 208 & 208 \\
\hline
\end{tabular}


Table 3 Correlations

\begin{tabular}{lllll}
\hline Model & $\mathbf{R}$ & $\begin{array}{l}\mathbf{R} \\
\text { square }\end{array}$ & $\begin{array}{l}\text { Adjusted } \\
\text { R square }\end{array}$ & $\begin{array}{l}\text { Std. error of the } \\
\text { estimate }\end{array}$ \\
\hline I & $.179 \mathrm{a}$ & 0.032 & 0.027 & 1.646
\end{tabular}

**Correlations is significant at the 0.01 level (2-tailed).

Table 4 Variables entered removed ${ }^{b}$

\begin{tabular}{|c|c|c|c|c|c|c|}
\hline \multicolumn{2}{|c|}{ Model } & \multicolumn{2}{|c|}{$\begin{array}{l}\text { Unstandardized } \\
\text { coefficient }\end{array}$} & \multirow{2}{*}{$\begin{array}{l}\text { Standardized } \\
\text { coefficients } \\
\text { Beta }\end{array}$} & \multirow[t]{2}{*}{$\mathbf{t}$} & \multirow[t]{2}{*}{ Sig. } \\
\hline & & B & Std. Error & & & \\
\hline \multirow[t]{2}{*}{ I } & (Constant) & 2.195 & 0.266 & & 8.267 & 0 \\
\hline & The project & 0.194 & 0.074 & 0.179 & 2.617 & 0.01 \\
\hline
\end{tabular}

\section{Roads and routs}

In highly industrialized countries, roads are the most important tools to carry out tasks and demands of a growing population and economy. ${ }^{14}$ The best possible thing is the proper use of roads. However, functional use of these funds is not sufficient and it should be viewed from an artistic, social, cultural and comfort perspective, as well. In Figure 1 beauty, harmony, proportion, composition, smoothness and density of lighting can be seen, but unfortunately there are not routers and guides for people to detect the end of the overpass bridge or underpass road direction and one may enter the underpass road by mistake while his/her purpose is achieved through the overpass bridge. Now we better realize that how this research project helps in all areas associated with the city.

\section{Conclusion}

Due to the divine nature of man gave to him by God; he is pursuant to welfare of other human beings and uses divine blessings to advance his goals. Light that is the infinite nature of God leads to the guidance and the recognition in humans. However, with advances in technology, we do not only need the solar energy to provide light and we have the ability to produce artificial light. Artificial light can be considered an element of public comfort, safety and health. Spatial quality can be maximized by lighting. But an integrated lighting with a target at the city level has never been largely implemented. By implementing a project like our research projects many variables are affected that are directly or indirectly related to the lives of humans. As a result, according to the enumerated objectives and qualities such as beauty, memorability, economy, locating, population growth and etc we began to basically design of the project, a lot of hidden and evident problems of the cities are removed.

\section{Acknowledgements}

None.

\section{Conflict of interest}

The author declares no conflict of interest.

\section{References}

1. Bekrani M, Mahdizadeh Siraj F. Lighting mechanism of monuments in urban areas, Case study of Sheikh Lotfollah Mosque. Journal of Iranian Architectural Restoration. 2013:99-110.
2. Oshidri J. Light, fire, Fire temple of Zoroastrianism. Iran: Markaz publications; 2000.

3. Nasr SH. Islamic art and spirituality. Indonesia: Tehran L Hekmat publications; 2010. 284 p.

4. Mahaleh AT, Kaveh. An introduction to the basics of lighting design. Iran: Designer; 2008.

5. Kasai M. Adormant who was awakened Danesh nama. 2004;102(104):46-50.

6. Phillips D. The Lite Environment. USA: Butterworth Arcgitectural Press; 2002.

7. Santen Cv. Lichtraum Stadt (LichtplanungimurbanenKontext). Basel Boston: Walter de Gruyter; 2006.

8. Khesali A, Voldan Zoj MJ, Mokhtarzadeh M. The integration of basic knowledge of radar high-resolution optical images, to extract the effects of roads in urban areas using context information. Research and scientific Journal of radar. 2013:27.

9. Tahbaz M. Pyramid/shady frame of window-simultaneous investigation of sun light and heat in the design of window over a one year period. Doctorate thesis of architecture. Tehran, Iran: Shahid Beheshti faculty of architecture and urban development; 2005.

10. Sanati L. Window and the sun-the designing principles of window based on the adjustment of light and shadow. Iran: Architecture MA's thesis; 2007.

11. Feizmand N. Architectural design consideration for the exploitation of daylight in Iran's arid climate educational buildings. MA's thesis of technical miner of architecture. Iran: Tarbiyat Modarres University faculty of art Tehran; 2011.

12. Kazemzadeh M. Modification of the design among the spaces (Atrium), for the improvement of thermal efficiency and exploitation of daylight in arid climate of Kerman buildings and particularly public buildings. Iran: MA's architecture thesis; 2001. 277 p.

13. Dennis K. Cars, Cities, Futures, published by the Department of Sociology. UK: Lancaster University; 2007. 35 p.

14. Kloor K. A Surprising Tale of Life in the City. Science. 1999;286(5440):34.

15. Te-qi D, Feng-jun J. Formation of Los Angeles low density and high car dependence. Journal of Chongqing University. 2009;8(1):25-31.

16. Tregenza P, Loe D. The design of lighting. UK: E \& FN Spon; 2004.

17. Winton A. Urban violence: a guide to the literature. Environment and Urbanization. 2004;16(2):165.

18. Wite R, Sutton A. Crime prevention, urban space and social exclusion. Australia: Department of Criminology University of Melbourne; 1995. 31(1):25.

19. www.aftabir.com

20. Ebrahimzadeh A, Hafez Reza Zadeh M, Daraei M. The optimal planning and locating of facilities and infrastructure for urban tourism by the use of GIS. Geography and Development. 2014;12(35):33-38.

21. Omidbakhshi M, Bagherinejad J, Saif Barqi M. Modeling the problem of a balanced locating using gravity model over the network and solving it using a heuristic approach. Journal of Industrial Engineering. 2011;45(2):117-130.

22. Azimi F, Mokhtari M, Suzangar F, et al. Surveys to determine areas of potential risk for physical development in GIS. Natural Geography Quarterly. 2012;5:27-36. 
23. Alidoost F, Mobasheri MR, Abkar AA. An efficient way to increase both spectral and spatial resolution in satellite images in an urban environment. Remote sensing and GIS of Iran. 2012:22.

24. Qasim N, Ahmari M. Natural Lanterns, identity approach in Helsinki lighting. Landscape. 2012;21:16.

25. Qorbani R, Jam Casra M. Walk-developmting movement, a new approach to revitalize urban centers, case study of Tarbiat walk side in Tabriz. Journal of Urban and Regional Research. 2010;2(6):55.

26. Gardner K, Moloni R. Change in the use of lighting, architectural retelling. Trans. Iran; 2007.
27. Mohseni Tabrizi A, Qahremani S, Yahak S. Defenseless urban spaces and violence, Case Study: Tehran defenseless spaces. Applied Sociology, Consecutive. 2011;44:52.

28. Mokhtari Malekabadi R. Analysis of parking applied planning in Isfahan using applied models of regional planning. Journal of Urban and Regional Research. 2009;1(3):115-134.

29. Monshizadeh A. Human, night, city: a review on Berlin light festival. Landscape. 2012:44-47.

30. Wahid Hussain A, Okhovat A. Out of the darkness. Danesh nama. 2004;102(104):54-58 